\title{
UN POEMA BIZANTINO RECIENTEMENTE EDITADO
}

\section{RAÚL LAVALLE \\ Argentina}

1 profesor italiano Lorenzo Viscido es un gran estudioso del mundo
antiguo y medieval. También es finísimo poeta latino. No pretendo extenderme aquí sobre sus sobrados méritos, que cualquier lector interesado encuentra hoy en la Red. Simplemente quiero agradecer aquí la deferencia que tuvo conmigo, pues me envió un muy reciente estudio. En él edita un poema: "Due sticheri inediti in onore di Sant'Acacio, martire di Bisanzio". Mi humilde tarea aquí será dar una versión española del himno griego; añadiré un comentario. Lo más importante, en todo caso, es que algún lector interesado acuda al citado artículo de Viscido.

\section{Texto griego}

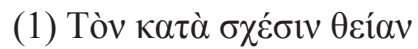

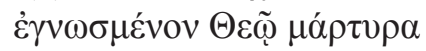

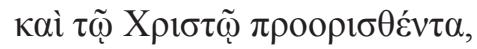

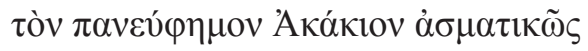

$\varepsilon \hat{\varphi} \varphi \mu \eta ́ \sigma \omega \mu \varepsilon v$.

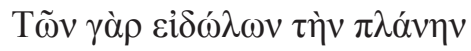

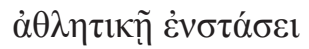

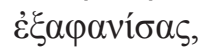

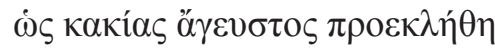

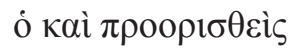

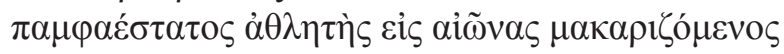

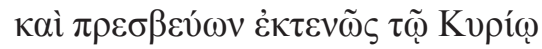

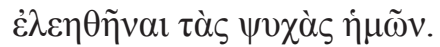

1 En: Analecta Bollandiana, 132 (2014), pp. 286-289. 
(2) 'H

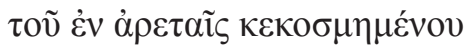

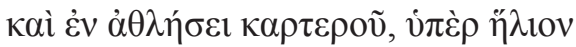

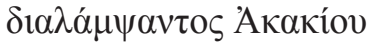

$\tau \tilde{\eta} \pi \alpha \rho \theta \varepsilon v i \kappa \tilde{n}$

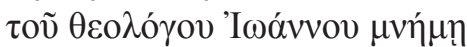

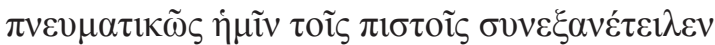

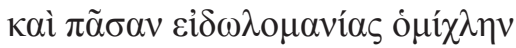

$\tau \tilde{\eta} \varsigma \dot{\varepsilon} \lambda \lambda \eta v i \kappa \tilde{\eta} \varsigma$

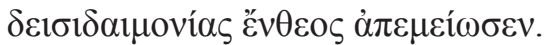

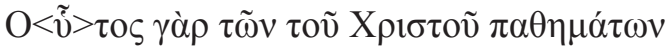

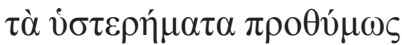

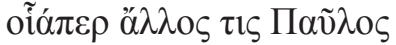

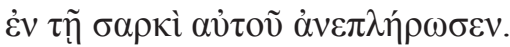

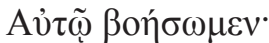

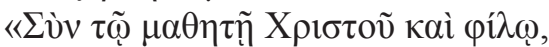

$\mu \varepsilon \gamma \alpha \lambda \circ \mu \alpha \alpha_{\rho} \tau \cup \varsigma$, i

$\tau$

\section{Traducción}

Celebremos nosotros en himnos al muy laudable Acacio, mártir conocido de Dios por su divino natural y que fue predestinado por Cristo. Pues borró del todo, con su muy atlética apostura, el engaño de los ídolos. No probó la maldad y así fue reconocido; como también fue predestinado este celebérrimo atleta, que será para todos siglos bienaventurado. Abogará tenazmente ante el Señor, para que haya misericordia para nuestras almas. 
La deslumbrante y bella fiesta de este varón adornado de virtud y fuerte en el combate, de Acacio que resplandece por sobre el sol, se ha levantado espiritualmente para nosotros fieles, con la virgen memoria de Juan el Teólogo; Acacio inspirado disminuyó toda niebla de la superstición pagana, enloquecida en su amor por los ídolos.

Pues él ha completado en su carne muy animosamente, cual otro Pablo, aquello que faltaba de los padecimientos de Cristo. Exclamemos entonces hacia él: "Junto con el discípulo amado de Cristo, oh tú muy excelso mártir, suplica a nuestro Señor, para que así sean salvadas nuestras almas."

Sobre San Acacio, baste aquí decir que fue mártir en Bizancio en el 303. En el comienzo del texto se nota en seguida la importancia de la raíz de $\varphi \eta \mu$ í. En efecto debemos 'decir bien' ( dicho' ( $\pi \alpha v \varepsilon v ́ \varphi \eta \mu \nu, ~ v . ~ 4)$ de quien todos hablan bien. Pero tal decir es especial: se transforma en canto, pues lo celebraremos $\alpha \sigma \mu \alpha \tau 1 \kappa \tilde{\omega} \varsigma$ (v. 4). También es importante la idea de conocimiento, pues Acacio no solo es 'conocido por Dios' (v. 2) sino que ha sido predestinado, $\pi \rho 00 \rho 1 \sigma \theta \dot{\varepsilon} v \tau \alpha$ (v. 3). Vale decir, Cristo le ha fijado un ópos, un 'límite', un 'confín'; le ha sido asignada una especie de suerte ( $\kappa \lambda \tilde{\eta} \rho \varsigma_{\varsigma}$ podría haberse dicho), que es la salvación a través del martirio.

En lo que llamaría yo la segunda parte de la primera estrofa ${ }^{2}$, se destaca

2 Tenga presente el lector que no domino el tema de la hímnica bizantina. Según me explica el prof. Viscido acerca de estos "sticheri idiomeli", estamos ante himnos que tienen metro y melodía propios, pero no sirven de modelo para otros cantos. Como tales difieren de los "automeli", los cuales tienen metro y melodía propios, pero sirven de modelo métrico-melódico para otros himnos; estos últimos son llamados “prosomi” (se ve la raíz de ő $\mu$ otos, 'semejante'). 
especialmente el esfuerzo, la lucha que supone el martirio. Para expresar la negación de sacrificar a los ídolos, y dentro de la gran tradición apologética, acude a la raíz de lo "atlético"; Acacio es 'atleta' (v. 11) del Señor; se vale de una 'atlética apostura' (v. 7). No necesito multiplicar ejemplos, pero demos unos pocos. Por ejemplo Eusebio de Cesarea habla de los 'atletas de Dios's; el mismo autor narra que en Cesarea de Palestina cierta mujer sostuvo un combate semejante (ő $\mu$ oıv $\alpha \dot{\alpha} \tilde{\omega} v \alpha \delta \eta \theta \lambda \eta \kappa \varepsilon ́ v \alpha 1)$ al que afrontaron los varones ${ }^{4}$. Y creo que todos conocen el antecedente último, que es la Epístola primera a los corintios, que habla de 'los que corren en el estadio' y agrega que 'todo aquel que combate ( $\pi \tilde{\alpha} \varsigma$ ó $\alpha \gamma \omega v i \zeta o ́ \mu \varepsilon v o \varsigma$ ) de todo se abstiene. ${ }^{5}$ También en la segunda

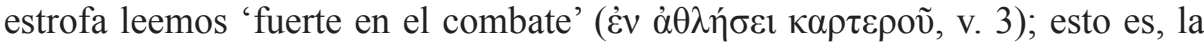
misma imagen de la fortaleza atlética.

Pero de la mentada segunda estrofa me impresiona vivamente el

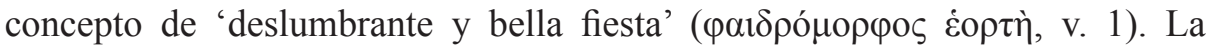
liturgia se complace en el brillo de la celebración y los fieles siempre han aguardado y gozado con avidez tal esplendor. Aquí, como en tantas otras cosas, el cristianismo bendice y toma como propio algo que está en la condición humana: el dies festus. Ya lo había señalado Pericles, pues Tucídides nos cuenta que, en el discurso que el gran estratega pronunció en favor de los muertos por su patria Atenas, una de las cosas justamente que alaba de la gloriosa ciudad es su espíritu festivo: "Para mitigar los trabajos tenemos muchos recreos, los juegos y contiendas públicas, que llaman sacras, los sacrificios y aniversarios que se hacen con aparatos honestos y placenteros, para que con el deleite se quite o disminuya el pesar y tristeza de las gentes"6. Tienen razón Pericles y Tucídides:

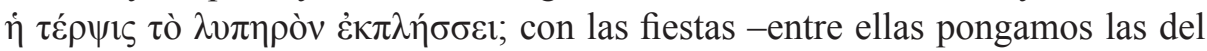
año litúrgico- nuestro ánimo se alegra in hac lacrimarum valle.

Me detengo un momento en $\delta \varepsilon 1 \sigma 1 \delta \alpha \mu \operatorname{cv}^{\alpha} \alpha$ (v. 10). Por supuesto, si sumamos raíces, ella significa 'temor por los dioses', 'superstición.' Aquí leemos que Acacio, con su valor de mártir, venció tal superstición griega por

3 Eusebio de Cesarea, Historia eclesiástica 6, 1.

4 Eusebio de Cesarea, Historia eclesiástica 7, 12.

5 Cf. 1Cor 9, 24-25.

6 Tucídides, Historia de la Guerra del Peloponeso 2, 38. Copio la traducción: http:// civilizacionclasica2011.wikispaces.com/file/view/TUCIDIDES. + Historia $+\mathrm{de}+\mathrm{la}+\mathrm{G}$ uerra+del+Peloponeso.pdf. 
los ídolos. Ahora bien, un clásico de la literatura apologética, la Epístola a Diogneto, usa la palabra pero no aplicada a los griegos sino a 'la superstición de los judíos.' ${ }^{7}$ En efecto el apologista diferencia el cristianismo respecto de los griegos, quienes veneran a dioses que fueron hechos por un artífice, y de los judíos. Estos últimos se caracterizan por un culto riguroso en exceso y por su 'superstición por los sábados' ${ }^{8}$. Acacio pudo enfrentarse y derrotar a ambos falsos temores y 'lleno de la divinidad', 'inspirado' ( $c ̌ v \theta \varepsilon o \varsigma$, v. 10) halló fuerzas necesarias para luchar por la fe.

Por último, fijo mi atención en $\tau \grave{\alpha}$ vं $\tau \varepsilon \rho \eta ́ \mu \alpha \tau \alpha$ (v. 12). Si Acacio es 'otro Pablo' (v. 13), está bien que siga la idea del Apóstol, de completar lo que falta en nosotros a la pasión de Cristo ${ }^{9}$. No soy teólogo pero, en una primera mirada, la idea de faltar, de que Jesús no hizo cumplidamente lo que hizo, me resulta por lo menos curiosa. Mas el propio Pablo lo aclara, creo: la pasión fue sobreabundante, pero Él nos pide que pongamos algo de nuestra parte, 'lo que falta.' Acacio puso su testimonio de sangre. En fin, como dije al principio, con mi traducción y mi nota invito a los lectores a conocer este nuevo trabajo del prof. Viscido; un segundo propósito, que se acerquen, si no lo han hecho, a la hímnica bizantina. Es un mundo por descubrir, que tiene los valores propios y los de su tradición griega milenaria ${ }^{10}$.

7 Epístola a Diogneto 1.

8 Epístola a Diogneto 4.

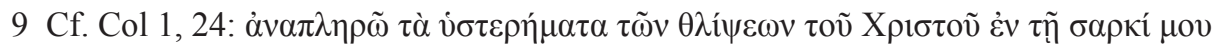

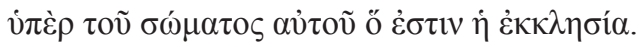

10 Me permito mencionar los trabajos sobre hagiografía bizantina de mi amigo el prof. Pablo Cavallero, de la Universidad de Buenos Aires y de la Universidad Católica Argentina. 